\title{
Ceramic-controlled piezoelectric: development, applications and potentiality in electrical and biomedical engineering
}

\author{
E. Suaste Gómez, C. O. González Morán and J. J. A. Flores Cuautle \\ Centro de Investigación y de Estudios Avanzados del Instituto Politécnico Nacional, \\ México
}

\section{Introduction}

In the solid-state materials there are the dielectrics called smart materials, which are those that have the ability to manifest qualitatively properties under the external influence, such as pyroelectric, piezoelectric and ferroelectric materials. Ferroelectric materials are those that exhibit spontaneously electrical polarization and the polarization has more than one possible equilibrium orientation, similar to ferromagnetic materials, ferroelectrics present "domains" or areas in which the polarization is oriented in certain crystallographic direction, by means of applying an intense electric field (E), it is possible to reorients the domains in the direction of the nearest electric field allowed by the material structure and inducing dipole moments inside matter. Independent of the structure of the constituent material a cylindrical symmetry in the polarized ceramics is induced (Jaffe \& Cook, 1971).

The fact that an applied E field induces dipole moments inside material objects has two common physical mechanisms for the creation of these induced dipole moments inside matter. The first is the rotation of existing polarized region ("dipoles") inside the material into partial alignment with the applied field. These sub regions can be individual molecules, as in the polar molecules of water, or domains consisting of thousand of atoms, as ferroelectric ceramics. The second mechanism is the creation of dipoles by charge separation of initially nonpolar atoms or molecules (Wai-Kai, 2005); in this case, the electron clouds are pulled in one direction by the Efield, while the positive nuclei are pushed in the opposite direction as shown in Fig. 1.

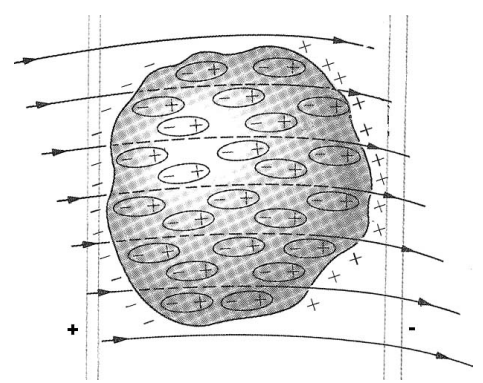

Fig. 1. Polarization of the material by an electric field to create dipoles through matter 
Among such piezoelectric materials, Barium titanate $\left(\mathrm{BaTiO}_{3}\right)$ and Lead Lanthanum Zirconate Titanate (PLZT) are well known materials. $\mathrm{BaTiO}_{3}$ is a ferroelectric classic perovskite structure and PLZT is a ferroelectric solid solution with wide-ranging material properties that depend on its composition (Moulson \& Herbert, 2003; Plonska \& Surowiak, 2006). Several studies have been carry out in order to study the influence of compositionally modified ceramic bodies, the addition of a variety of elements to obtain a doped ceramic is one of the most important research line, another line is the study of multilayer capacitors based on these materials, having these concepts in mind, a metallic wire implanted in the transversal way in the middle of a ferroelectric ceramic is use as control electrode, once upon the ceramic is poled this piezoelectric bulk is called ceramic-controlled piezoelectric $(\mathrm{CCP})$, the metallic wire has more than one propose in the ceramic: using this wire implanted, a free ceramic face is obtained, this face is used in order measure optic and mechanic events, the wire in total immersion into the ceramic serve as control electrode which allows to develop several applications.

Recently, we have fabricated bulks of $\mathrm{BaTiO}_{3}$ single plate and PLZT single plate, using a Ptwire of $300 \mu \mathrm{m}$ of diameter, this wire was implanted into ceramics to get a free face in order to measure optic and mechanic events. Our structure design includes a modified electrode configuration. The Pt-wire was chosen as implant because it possesses high resistance to chemical attack, it has excellent high-temperature characteristics (melting point $1768.3 \circ \mathrm{C}$ ), and it has a stable electrical properties and thermal conductivity with small variations (Touloukian et al., 1970).

When CCP is polarized, the mobile charges in the Pt-wire accumulate on the surface until the field they produce completely cancels the external applied field within Pt-wire, thereby producing equilibrium. Then inside Pt-wire which is in electrical equilibrium, the electrical field is zero as shown in Fig. 2. By this statement, we really mean that the net charge is distributed over a section of the surface having a thickness of several atomic layers not in the geometrical sense (González \& Suaste, 2009).

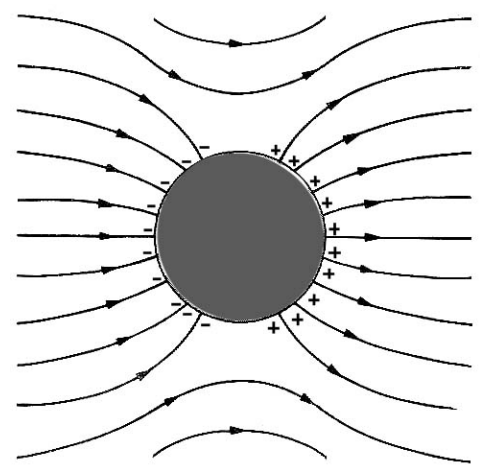

Fig. 2. Electric field waves a cross Pt-wire (top view).

The Pt-wire cylinder dimensions are $10 \mathrm{~mm}$ high and $0.3 \mathrm{~mm}$ diameter, this superficial area is $9.42 \mathrm{~mm}^{2}$. The superficial area of one side face of the ceramic is $78.53 \mathrm{~mm}^{2}$. When we compare this both superficial area, the ceramic is 8.33 times greater than Pt-wire superficial area. 
Pt-wire implanted into PLZT ceramic bulk develops a singular performance in the CCP due to the domain's coating on Pt-wire. This type of domain wall separates domains polarized perpendicularly to each other and when CCP is polarized the field should be such as to exert opposite torques on the polar axes of opposite domains, but not large enough as to permanently rotate the polarization. A similar effect is obtained by applying a suitable stress to the ceramic, as the piezoelectric effect has a different sign in antiparallel domains. When $\mathrm{CCP}$ is poled, over Pt-wire is originated a great concentration of domains due to dipoles were oriented over all external part of itself. These concentrations achieve free flux charges around Pt-wire when CCP is excited by stress or LASER illumination on the side face as shown in Fig. 3.

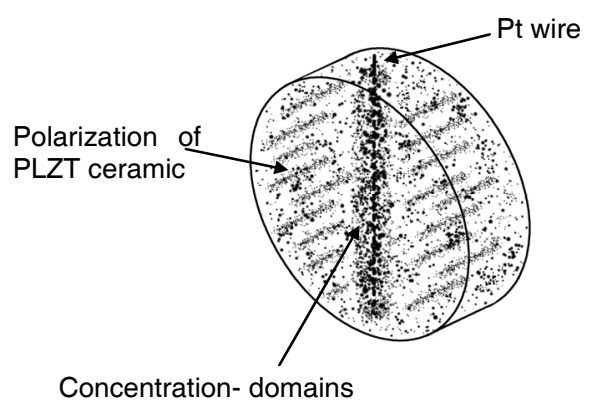

Fig. 3. Scheme from CCP and its distributed domains in around Pt-wire

Considering that ferroelectric and piezoelectric materials can be used as sensors and actuators. Piezoelectric pressure and acceleration sensors are now commercially available as well as a variety of piezo-vibrators. The development of ultrasonic motors for a variety of new applications has been exhibited and widespread in recent years. Besides, ferroelectric materials generally have excellent electro-optic properties due exhibit photovoltaic effects under near-ultraviolet light and thus seen as promising candidates for application in optical communications systems of the future using Pt implants.

When the PLZT is illuminated after poling, voltage and current can be generated due to the separation of photo induced electron and holes by its internal electric field. This is because the photovoltaic effect occurs within the material and is considered to be an optical property of the material itself and show application potentials for realizing energy transfer in micro electromechanical systems and optoelectronic devices (Sturman \& Fridkin, 1992; Ichiki et al., 2004, 2005).

The sample fabrication, how the CCP behaves to the temperature on its dielectric constant (with and without implant), the ceramic structure, mechanical and optical performance, and some important applications are described in the following sections (Suaste et al., 2009). 


\section{Fabrication}

The oxide-mixing route is the most used method for commercial purposes although it has several limitations, like difficulties in achieve microscopic compositional uniformity, is one of the cheaper methods to get ferroelectric ceramics, the method involve the general steps: mixing and grinding, calcination, grinding, shaping, densification, and finishing, which will be next briefly described.

Mixing: the raw powders are weighted in an appropriated portion with an allowance for the impurity and moisture content, the grain size is uniformed by grinding usually this part is wet by means of include some liquid to agglutinated the powder.

Calcination: the calcinations purpose is to begin the reaction by the firing the powders at temperatures around $800-1100^{\circ} \mathrm{C}$ depending of the material kind, this step not always is necessary, it depends on the material kind.

Shaping: in this stage the required dimensions and shape are forming by molding the powders and applying pressures that are around $75-300 \mathrm{MPa}$, is in this step that a $\mathrm{Pt}$ - wire is put into the middle of the ceramic in transversal way in order to obtain the third electrode.

Densification: also know as firing, it is made in a refractory recipient and at temperatures of 80 to $90 \%$ of material melting temperature in which the constituent ions have the mobility for the solid state sintering process take place.

Finishing: the finishing involves the polishing, machining (if it is necessary), and metallizing.

In our case the ceramic design includes a modified electrode configuration described as follows: a Pt-wire as control electrode in total immersion into the ceramic, the function of this extra electrode is to provides mobile charges in the ceramic, Pt-wire implanted into Lanthanum modified PZT (PLZT) and Barium titanate ceramic bulk develops a particular performance in the $\mathrm{CCP}$ due to the domain's coating on wire and increases the analysis area as Fig. 4 . shows.

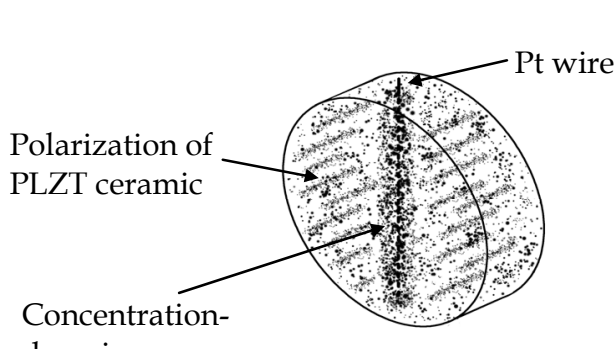
domains a)

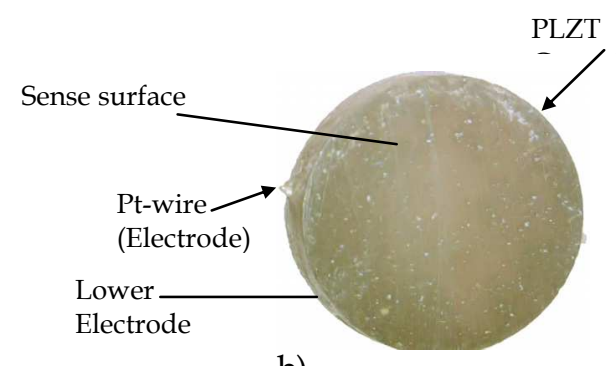

b)

Fig. 4. a) Diagram of Pt-wire position in piezoceramic and domains representation, b) PLZT ceramic image

Energy Dispersive Spectroscopy (EDS) was made in order to verify the chemical interaction between Pt-wire and ceramic, this analysis was made in the Pt-wire ceramic boundary, Ptwire and ceramic and reveals that no chemical reaction occurs as shown in Fig. 5. 

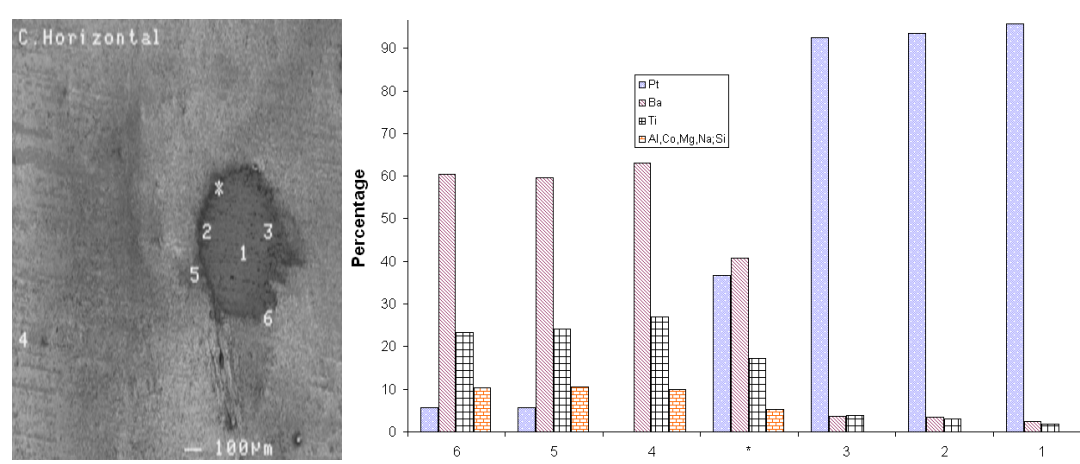

Fig. 5. Scanning Electron Microscopy (SEM) and EDS made in a barium titanate ceramic with Pt-wire implanted, numbers and $\left(^{*}\right)$ represent points in which an EDS was made.

Studies of the dielectric constant $\varepsilon$ as function of temperature in $\mathrm{BaTiO}_{3}$ and PLZT ceramic samples (with and without Pt-wire) were carried out. Curie temperature $\left(\mathrm{T}_{\mathrm{c}}\right)$ was measured by the dielectric constant method.

Samples were heated at a rate of $10{ }^{\circ} \mathrm{C} / \mathrm{min}$, until $600{ }^{\circ} \mathrm{C}$, the capacitance was measured at $1 \mathrm{kHz}$ with a Beckman LM22A RLC bridge. The dielectric constant was determined by expression 1.

$$
\varepsilon=\frac{C l}{\varepsilon_{0} A}
$$

Where $C$ is the capacitance in $F, l$ is the thickness of the sample in $\mathrm{m}, A$ the sample area in $\mathrm{m}^{2}$ and $\varepsilon_{0}$ the vacuum permittivity $=8.85 \times 10^{-12} \mathrm{~F} / \mathrm{m}$.

Results are shown in Fig. 6 for $\mathrm{BaTiO}_{3}$ and PLZT ceramics respectively and indicate that $\mathrm{T}_{\mathrm{c}}$ for $\mathrm{BaTiO}_{3}$ remains equal and PLZT has a $15^{\circ} \mathrm{C}$ shift while dielectric constant drops from 3916 to 2846 and 6923 to 5889 with Pt-wire for $\mathrm{BaTiO}_{3}$ and PLZT respectively.
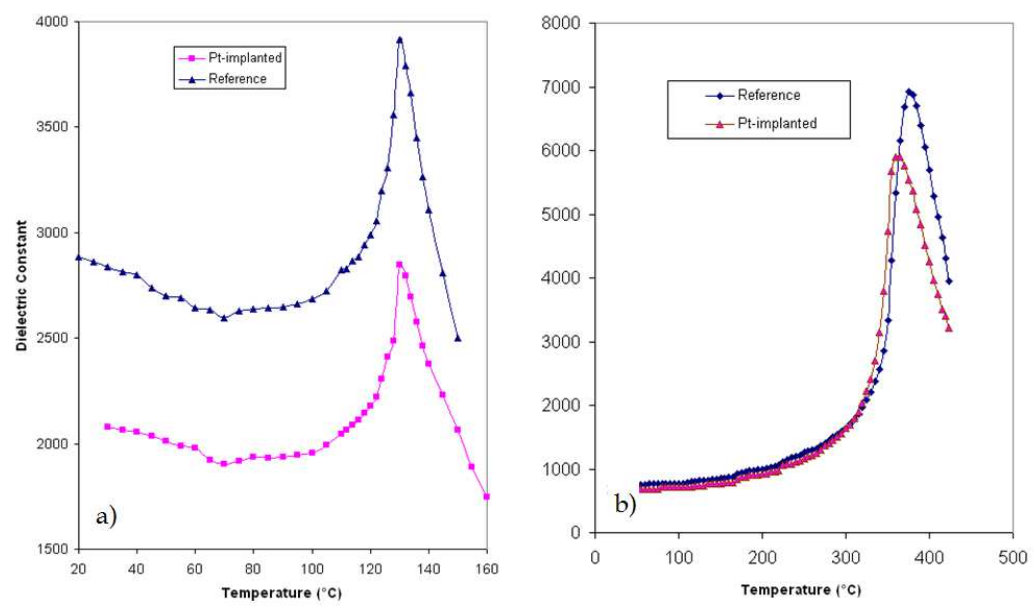

Fig. 6. Dielectric constant piezoelectric ceramics: a) $\mathrm{BaTiO}_{3}$ and b) PLZT. 


\section{Experimental Setups}

To validate and determine sensible characteristics of the $\mathrm{CCP}$, two experimental setups (mechanical and optical) were used. Over a free side face of CCP were selected six random specific zones to get optical and mechanical signals as shown Fig. 7.

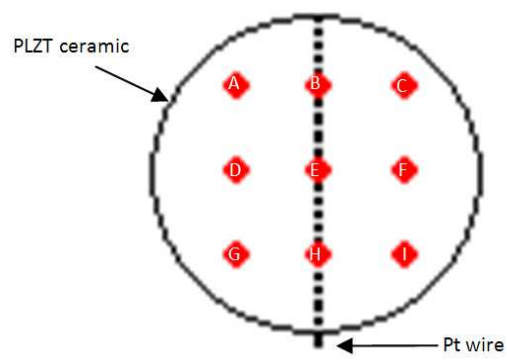

Fig. 7. Selected zones for realizing optical and mechanical analysis.

\section{Optical setup}

Figure 8 shows, the first experimental setup, to obtain the photovoltaic current magnitude, of those six zones, a fiber-coupled LASER system BWF1 mod, BWF-65015E/553369 modulated at $3 \mathrm{~Hz}$ of frequency with a wavelength of $650 \mathrm{~nm}$ and a maximum LASER illumination of $160 \mathrm{~mW} / \mathrm{cm}^{2}$ were used. We include a set of lenses to reduce the LASER beam spot to a $0.5 \mathrm{~mm}$ of diameter size. The CCP was placed on an X-Y translation microscope stage. The electrical contacts from CCP were connected to an SRS-Low Current Noise Preamplifier SR570 to get records. Those records were registered by an Oscilloscope Agilent DSO3062A measuring their peak to peak voltage to construct its graphics which the $\mathrm{Z}$-axis is the magnitude of the photovoltaic current of each record.

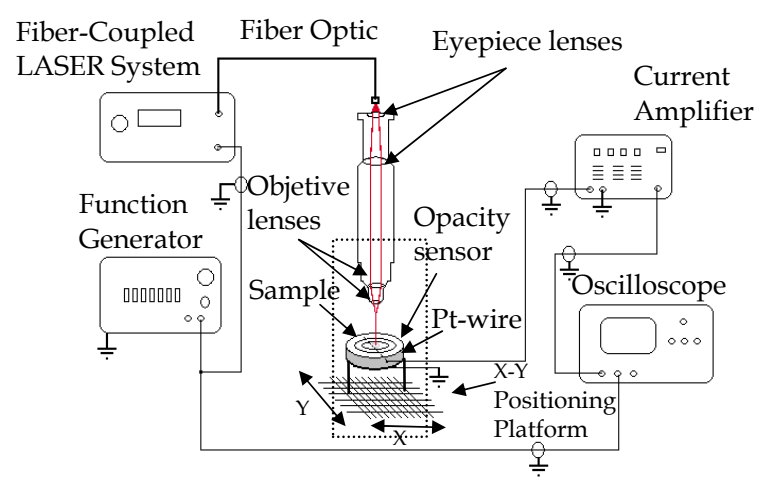

Fig. 8. Experimental setup to determine the ceramic sensibility of six random zones 


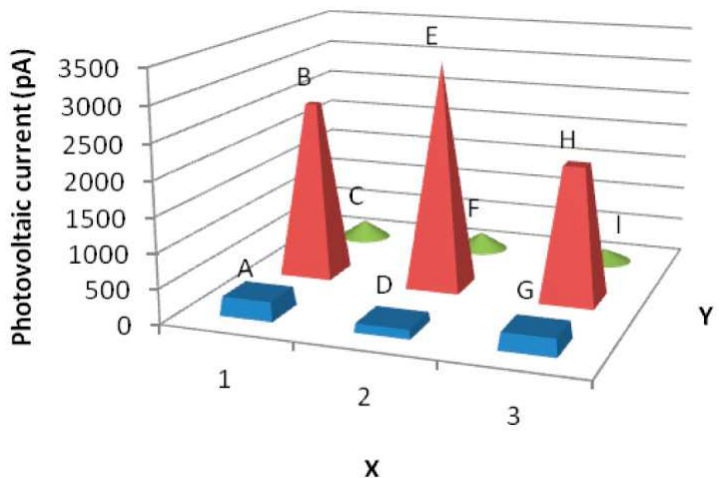

Fig. 9. Photovoltaic current generated by an illumination of $160 \mathrm{~mW} / \mathrm{cm}^{2}$ on six zones of CCP.

\section{Mechanical setup}
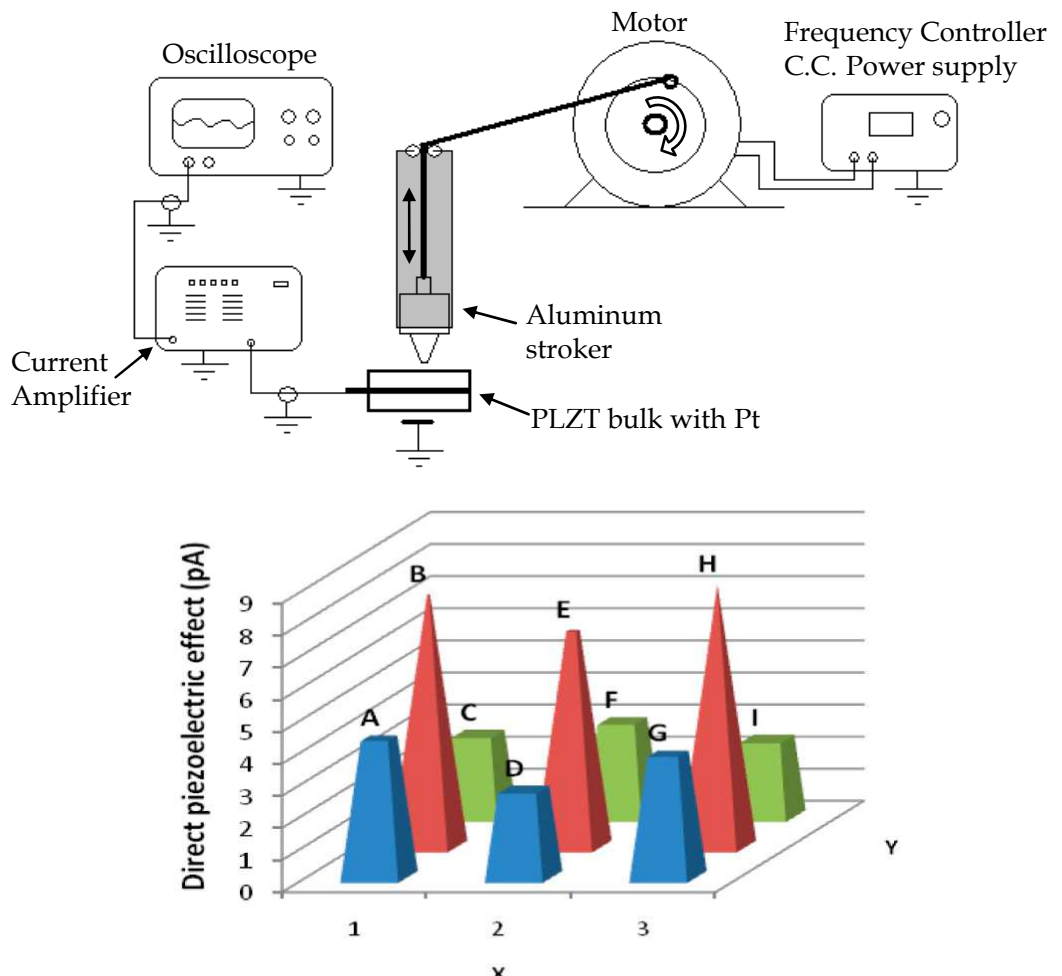

Fig. 10. Electrical current was generated by a force of $53 \mathrm{mN}$ on six zones of CCP.

This setup consists of constant weight pulse (gram-force) at a frequency of $2.26 \mathrm{~Hz}$ over the $\mathrm{CCP}$ in the same zones such as optical setup. The components of this setup were on a $24 \mathrm{~V}$ 
CD control motor Micro Switch 33VM82-020-11. The CCP was struck in a pulsed form controlled by a mechanism developed in our laboratory the experimental setup is described in Fig. 10. The force applied was $53.9 \mathrm{mN}$ and signals were record in a SRS-Low Current Noise Preamplifier. Those records were registered by an Oscilloscope Agilent measuring their peak to peak voltage to construct its graphics which the Z-axis is the magnitude of the photovoltaic current of each record.

\section{Applications}

\section{Optical applications}

Due to pyroelectric properties that $\mathrm{CCP}$ has, it is possible to develop low frequency sensors which allow detecting some light wavelengths from ultraviolet to infrared, as show in the next three experimental setups.

The first optical application consisted of obtaining an electrical signal of CCP between a side face and the Pt-wire electrode due to pulsed LASER beam that affected the opposed side face, for the stimulus it was used a He-Ne LASER and an optical chopper. The reference signal was obtained from controller chopper output and CCP signal was increased and recorded by a Low-Noise Current Preamplifier and Oscilloscope respectively.

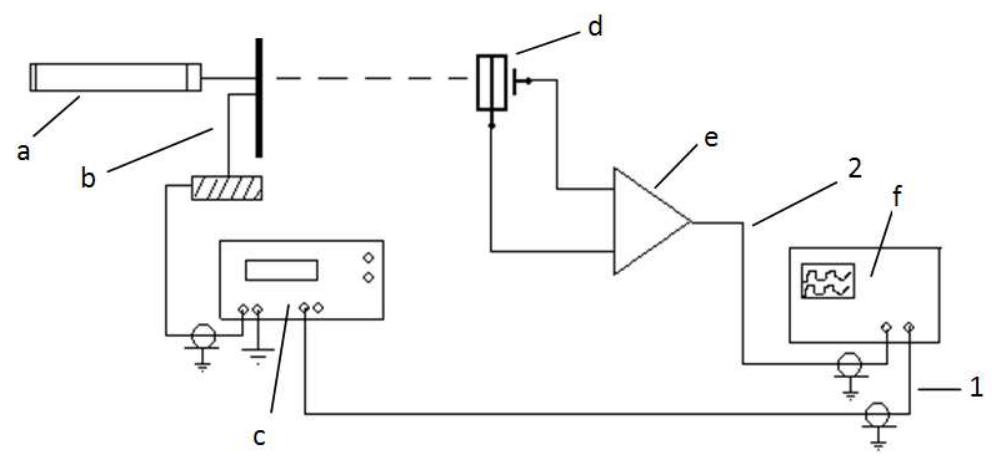

Fig. 11. CCP used as pulsed LASER beam detector. a) He-Ne LASER, b) Optical Chopper system, c) Chopper controller system d) CCP, e) Amplifier, f) Oscilloscope.

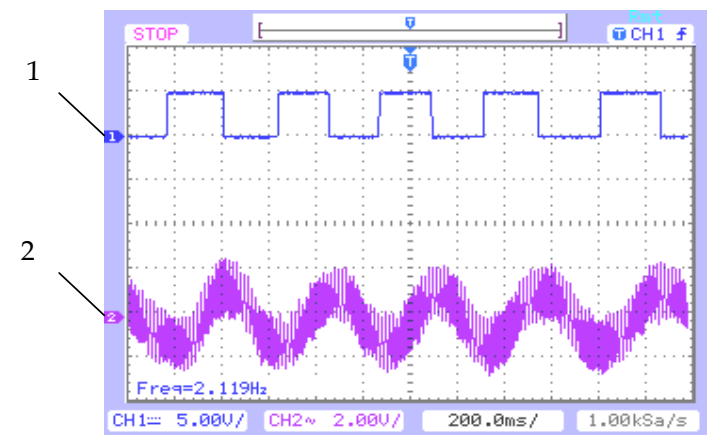

Fig. 12. Graphics from schematic setup, 1) Chopper pulse signal (reference) $2.11 \mathrm{~Hz}$ 2) Signal obtained from CCP $2.11 \mathrm{~Hz}$ 
In the second optical application, CCP was used as visible light detector; a stroboscope was used to a $3.1 \mathrm{~Hz}$, the light sparkles in one of the faces of CCP to a distance of $5 \mathrm{~cm}$ and on the sensor of a Standard Light Detector. Electrical signals were obtained, magnified and registered in an oscilloscope.
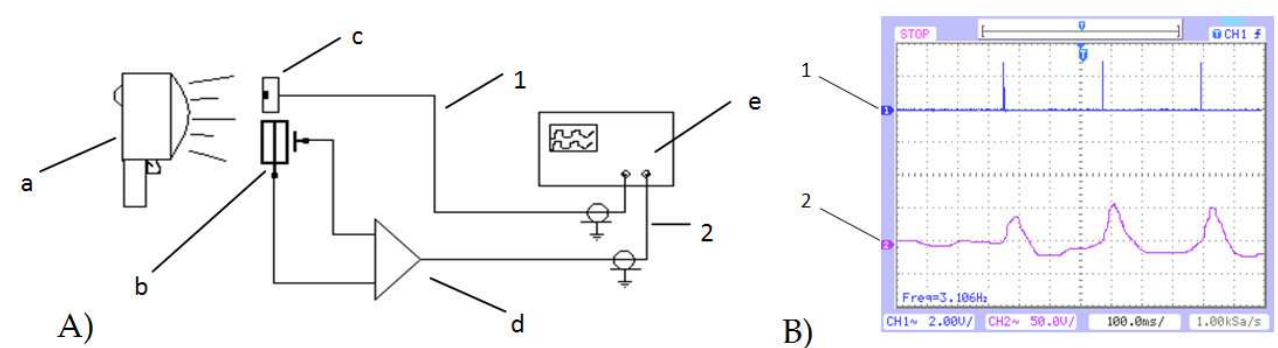

Fig. 13. CCP used as visible light detector. A) Schematic diagram, a) Stroboscope, b) CCP, c) Standard Light Detector, d) Amplifier, e) Oscilloscope, B) Graphics from schematic setup, 1) Reference signal from Standard Light Detector, 2) Amplified signal from CCP.

The third application is an acoustical-optical application where CCP is used as sound emitter; its electrical AC source was $60 \mathrm{~Hz}$ at $270 \mathrm{~V}$ Peak-Peak, this sound was detected by a metallized PVDF film which reflects He-Ne LASER beam to a Standard Light Detector DETN12 as shown in Fig. 14(A). The electrical responses from PVDF film and Standard Light Detector were observed in the oscilloscope, Fig. 14(B).

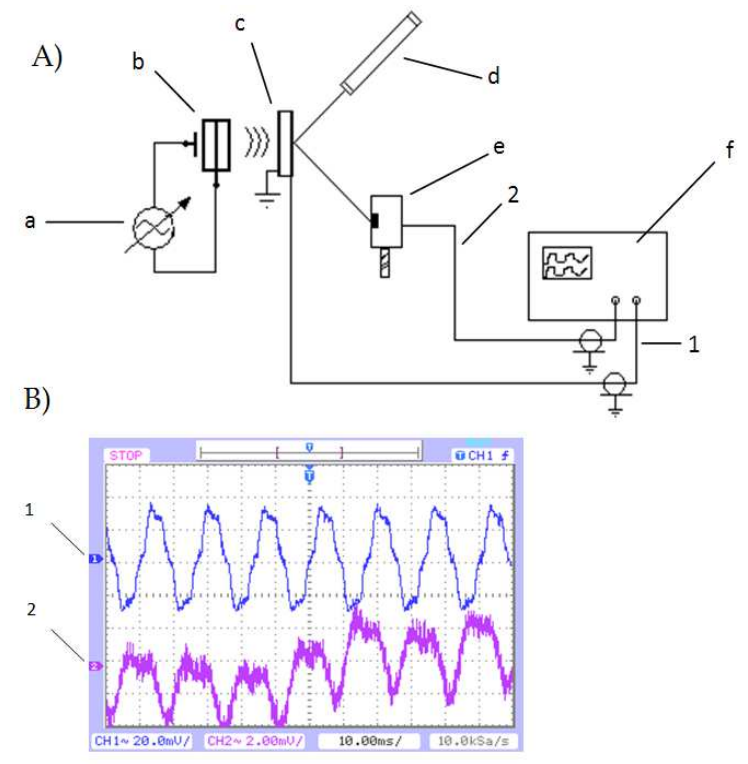

Fig. 14. CCP used as acoustical-optical sound emitter, detected and modulated optically with PVDF. A) Schematic diagram, a) $60 \mathrm{~Hz}$ at $270 \mathrm{~V}$ Peak-Peak source, b) CCP, c) Metallized PVDF film, d) He-Ne LASER, e) Standard Light Detector, f) Oscilloscope, B) Graphics from schematic setup, 1) Reference PVDF signal, 2) Signal obtained from Standard Light Detector. 
In the optical applications, it is possible to be appreciated that He-Ne LASER beam in one of the side faces of $\mathrm{CCP}$ was register satisfactorily and that was compared with the chopper controller signal is illustrated in Fig. 11. Also, CCP is sensible to visible light on one of side faces of $\mathrm{CCP}$ that was compared with reference light detector and obtained a waveform as shown in Fig. 13. Additionally, on operation mode of acoustical-optical, CCP worked as a good sound emitter of AC signal having as a receiver a PVDF film, demonstrated in Fig. 14.

\section{Mechanical Application}

Mechanical application, CCP was used as impact sensor on a $24 \mathrm{~V}$ CD control motor Micro Switch 33VM82-020-11 with dc analog tachometer included, CD motor was struck in a pulsed form controlled by a mechanism developed based on a relay system controlled by push bottom is illustrated in Fig. 15(A). The acquisition was realized from the tachometer output (reference signal) and CCP side face and Pt-wire electrode, both signals were registered in an oscilloscope and displayed in Fig. 15(B).

Mechanical, in Fig. 15(A) shows the CCP as well as a good vibrations sensor and the obtained graphics by CD motor tachometer and CCP were displayed in Fig. 15(B).

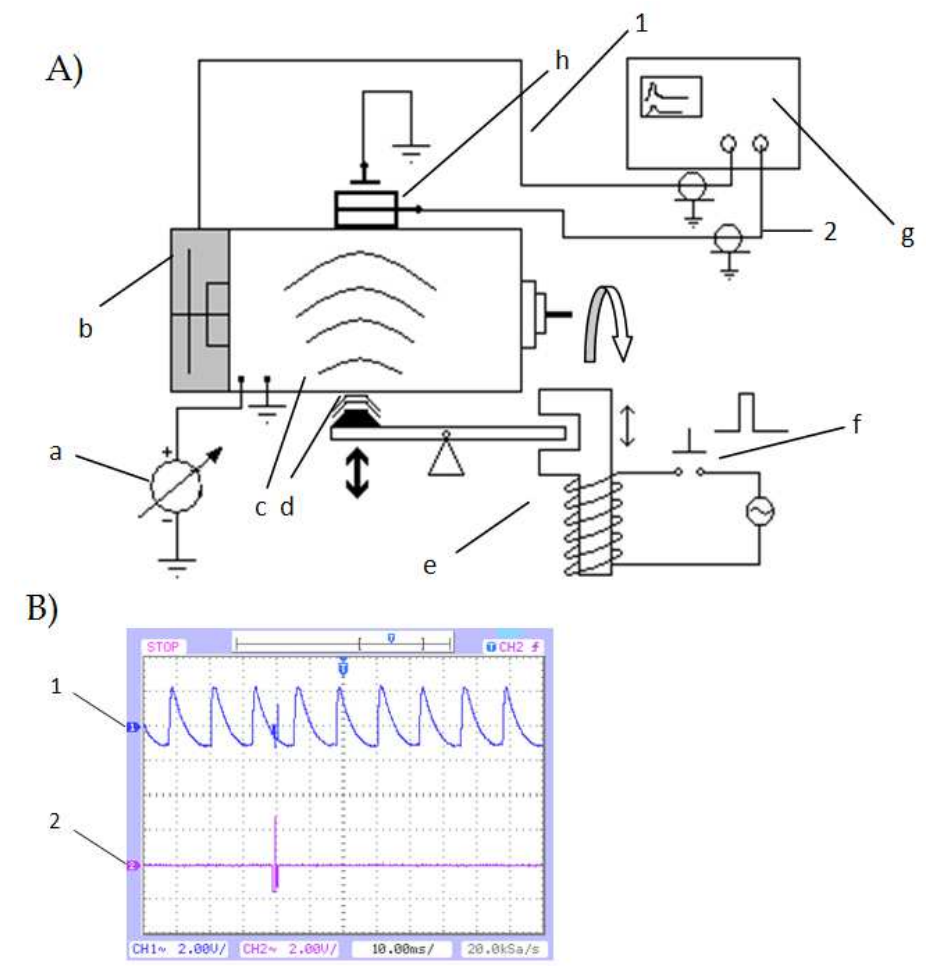

Fig. 15. CCP used as vibrations detector. A) Schematic diagram, a) DC Source, b) Tachometer, c) DC motor, d) struck zone, e) Impact pulsed device, f) Controlled push bottom, g) Oscilloscope, h) CCP, B) Graphics from schematic setup, 1) Signal from tachometer, 2) Signal from CCP. 


\section{Thermal application}

Thermal application, CCP was used as pyroelectric sensor from $25{ }^{\circ} \mathrm{C}$ to $80{ }^{\circ} \mathrm{C}$ obtaining change of current. CCP was coupled onto external surface of a furnace with a hole, in Fig. 16(A), acquisition temperature is shown. To measure current signal, it was put as reference a digital thermometer and for obtaining of variation in electric charge (or current) in an amperemeter, illustrating the tendency of the variation of electrical charges of CCP as shown in Fig. 16(B). Thermal, also responds to the changes of temperature as pyroelectric sensor with an ascending tendency as is demonstrated in Fig. 16(B).
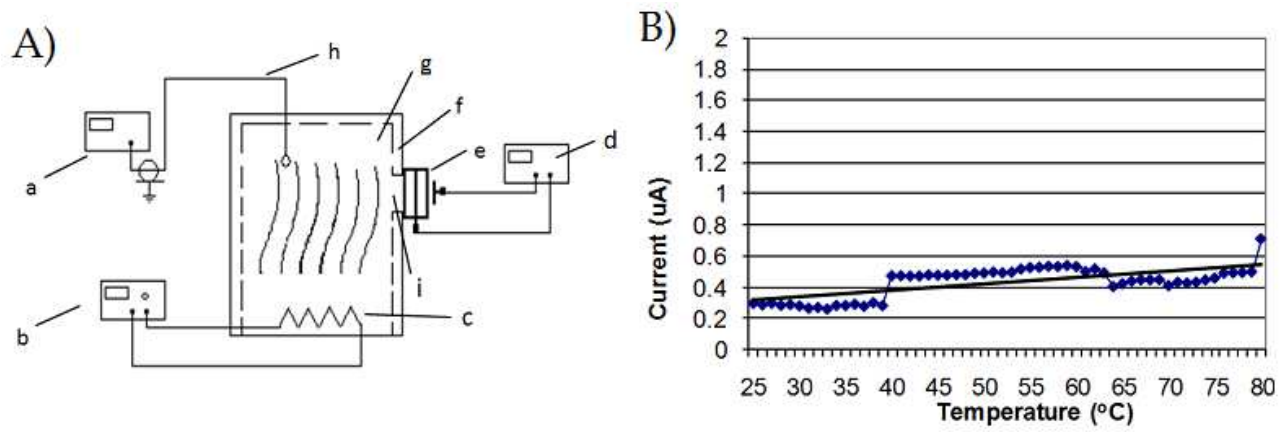

Fig. 16. CCP used as pyroelectric sensor. A) Schematic diagram, a) Digital thermometer, b) Temperature Control, c) Heater, d) Amperemeter e) CCP, f) Thermal Isolation, g) Furnace, h) Temperature Sensor, thermocouple type J, i) Furnace test window, B) Current graphic, I) Signal recorded from CCP, II) Tendency from signal recorded.

\section{Electrical applications}

For electrical application, three experimental setups were used. In the first electrical application, CCP was used as resonant element of high frequency oscillator based on CMOS inverter (Frerking, 1978), where Pt-wire electrode is connected to ground and high frequency signal of $41.66 \mathrm{MHz}$ were obtained from logical inverter output is illustrated in Fig. 17(A). This signal was registered in an oscilloscope as Fig. 17(B) is displayed.

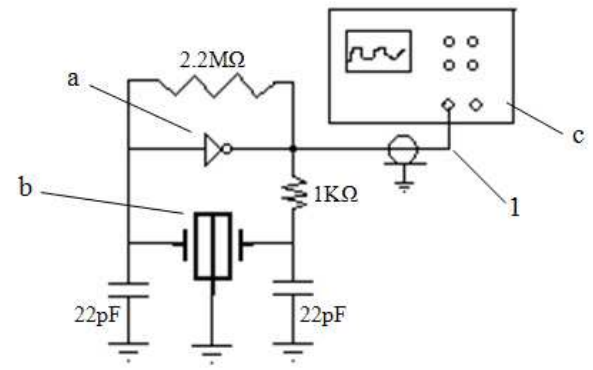

A)

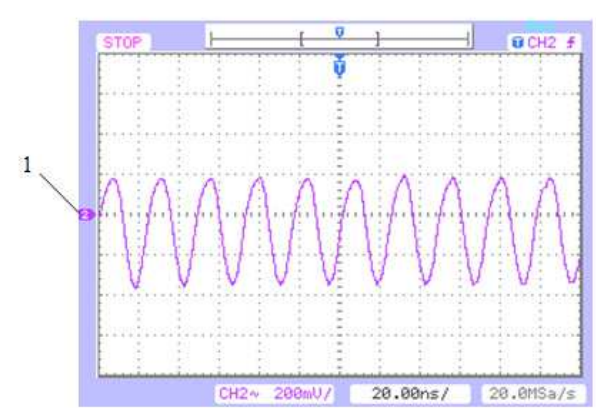

B)

Fig. 17. CCP used as oscillator in a parallel resonator circuit. A) Schematic diagram, a) CMOS inverter, b) CCP, c) Oscilloscope, B) Graphics from schematic setup, 1) Signal obtained $41.66 \mathrm{MHz}$ 
When CCP is tried as important part of a high frequency oscillator circuit, it works well connecting Pt-wire electrode to ground illustrated in Fig. 17. Using the same electrical circuit but now adding a signal generator (sinusoidal, triangular wave or square wave) to $\mathrm{Pt}$-wire electrode input, superposition of high and low frequency waves were obtained in Fig. 18.

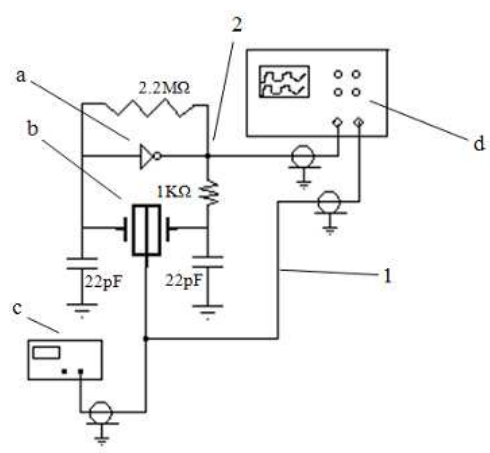

A)
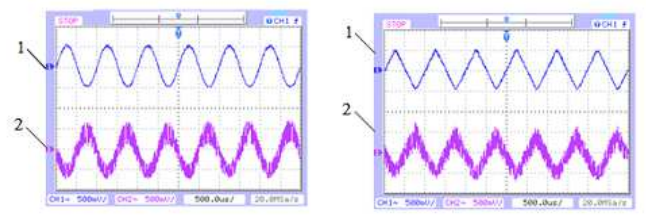

B)

Fig. 18. CCP in a parallel resonator circuit enabling Pt-wire electrode as input signal. A) Schematic diagram, a) TTL inverter, b) CCP, c) Signal generator, d) Oscilloscope, B) Graphics from schematic setup, 1) $10 \mathrm{KHz} \mathrm{CCP}$ input signal (sinusoidal, triangular wave, square wave) in Pt-wire electrode, 2) Wave superposition signals obtained from logical inverter output.

Electrical application, CCP as it bases of a logic gates. Fig 19(A) illustrates schematic diagram where CCP is exposed to two TTL signals, input S1 in one side face electrode was $2.5 \mathrm{KHz}$, input S2 in the other side face electrode was $10 \mathrm{KHz}$ and output S3 was in Pt-wire electrode. As result of S3, it has a (offset zero) displaced giving rise to that the signal has positive and negative values (5.84 V Peak-Peak). The output S3 exhibits a clearly suppression of logical pulses ( 0 and 1) from S2 at the moment that S1 is in positive (digit value " 1 ") and no suppressing pulses ( 0 and 1 ) while $S 1$ is negative (digit value " 0 ") as shown in Fig. 19(B).

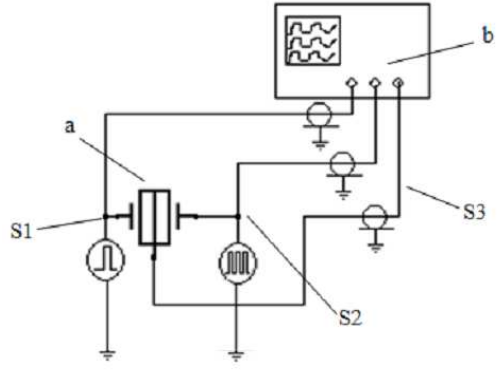

A)

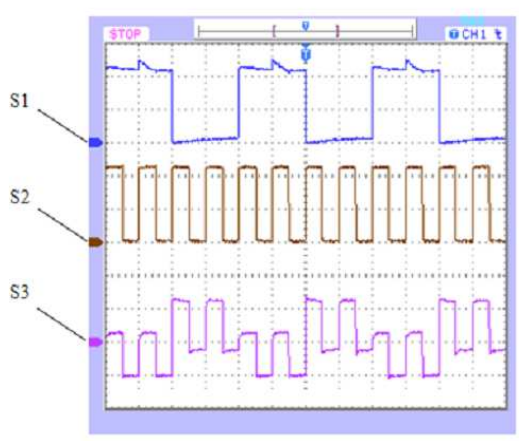

B)

Fig. 19. CCP used as it bases of logic gates obtained of two digital TTL signals. A) Schematic diagram, a) CCP, b) Oscilloscope, B) Graphics from schematic setup, S1) $2.5 \mathrm{KHz}$ TTL input signal on CCP electrode, S2) $10 \mathrm{KHz}$ TTL input signal on electrode of CCP, S3) 5.04 V PeakPeak output signal obtained from Pt-wire electrode. 
Adding a diode on output S3 is possible to eliminate negative part from signal. Thus, to obtain an equivalent logic gate that it explains the behavior of the circuit, a truth table is realized such as Table I. In addition, getting from it a Boolean function by means of Karnaugh maps (Maini, 2007) resulting a $F_{1}$ and $F_{2}$ Boolean expressions, where $F_{1}$ implementation is a logic gate NOR with inverted input $S 2$ and $F_{2}$ is a logic gate AND with inverted input S1, illustrated in Fig. 20.

Logical application, CCP associated to digital signals is appraised great versatility of the device, which allows glimpsing to the CCP like a device to be used similar to the logic gates demonstrated in Fig. 20.

\begin{tabular}{|l|l|l|}
\hline S1 & S2 & S3 \\
\hline 0 & 0 & 0 \\
\hline 0 & 1 & 1 \\
\hline 1 & 0 & 0 \\
\hline 1 & 1 & 0 \\
\hline
\end{tabular}

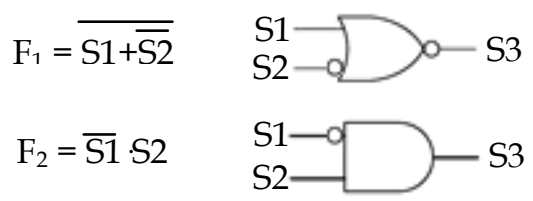

Fig. 20. Truth table for CCP obtained from waveform timing diagram as shown in Fig. 17(B), in the left Boolean expressions F1 and F2 and their implementations. The result of F1 it was a logic gate NOR with inverted input S2 and the result of F2 was a logic gate AND with inverted input S1.

\section{Biomedical engineering applications}

\section{Piezoelectric Plethysmograph sensor based on Lead Lanthanum}

\section{Zirconate Titanate bulk ceramic-controlled piezoelectric, implanted with Pt wire}

Piezoelectric methods seem to be the most promising for skin microcirculation studies; the analysis of the skin mechanic pulse piezoelectric detection provides valuable selective information on blood flow on upper skin layers, cutting off the influence of the deeper arteries and veins (Caro, 1978). CCP offers a great variety of applications in medical physics such as the human pulse detection called piezoelectric plethysmograph sensor (PZPG).

The periodical increase of blood volume in micro-vessels due to their dilatation during the systolic raise of pressure with the following diastolic contraction over each heartbeat causes corresponding changes in the absorption of the mechanical signals which travel within the working volume. The human vascular system is elastic and multi-branched, and each branching partially reflects back the pressure wave (Janis, 2005).

The experimental setup used in order to get the patient's cardiac pulses was as follows: he was placed in a supine position and in order to record the electrical activity of his heart, the electrocardiographic (ECG) electrodes were placed on the lead I, the PZPG was placed on the index finger of the patients' left arm, as shown in Fig. 21 in order to measure the blood flow that results from the pulsations of blood occurring with each heartbeat. The ECG and PZPG signals were registered and measured their peak to peak voltage. PZPG sensor 
guarantees electrical isolation of the patient. Its size PZPG can be adjusted to the fingertip measurements, it can easily be extended by means of spare bands, therefore it is possible to take PZPG measurements from different locations of the body, e.g. forehead, forearm, knee, neck, in this context it is possible to use the CCP as base of frequency modulated transmitter, in this mode the modified ceramic is used as part of resonator circuit in an oscillator at the same time an electrocardiographic signal is applied to the CCP by the Ptwire having as result a frequency modulated signal (Gutierrez \& Suaste, 2009).

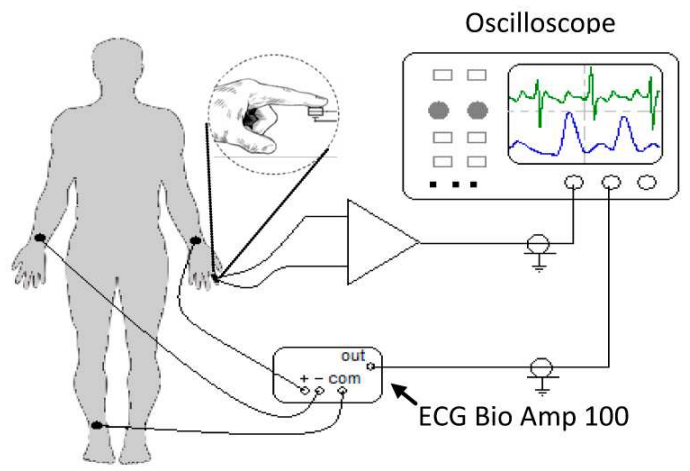

Fig. 21. Experimental setup of Piezopletysmograph in order to obtain fingertip pulses

\section{Opacity sensor (OPS) based on photovoltaic effect of Ferroelectric PLZT ceramic with Pt wire implant}

When the PLZT is illuminated after poling, voltage and current can be generated due to the separation of photo induced electron and holes caused by its internal electric field. This is considered an optical property of the material itself which has potential applications for supplying energy transfer in microelectromechanical systems and optoelectronic devices (Sturman \& Fridkin, 1992). The steady current in the absence of applied voltage, called photocurrent, is considered the result of photo carriers and the asymmetric electromotive force induced by near-ultraviolet radiation (Tonooka et al., 1998). Therefore, photocurrent is a very important parameter for optical detection (Qin et al., 2007). The behavior of the photovoltaic effect in ferroelectrics is similar to that of the photovoltaic effect in semiconductor $\mathrm{p}-\mathrm{n}$ junctions.

The semiconductor p-n junction is an interface; in order to extract an electrical output, it is indispensable to apply a bias voltage to it; however, this electrical stimulus is unnecessary for producing the photovoltaic effect on ferroelectrics.

There are three types of photovoltaic samples (Kobayashi et al., 2005) namely, a bulk single plate (Morikawa et al., 2000), a bulk bimorph (Brody, 1983) and film (Ichiki et al., 2006). The single plate exhibit high voltage; the bimorph has a large degree of distortion, fast mechanical response, and is suitable for mechatronics; the film shows a high current output and is a good current source for the optical sensor of the MEMS. Thus, the output power of the film is still one order of magnitude lower than that of the bulk structures reported here. This new type sensor has some interesting advantages such as free upper face (it is not necessary to add any electrodes), it is a better voltage source than multilayer film PLZT and 
the output from the photovoltaic effect of bulk PLZT is controllable by only varying the light intensity (Ichiki et al., 2005).

The thickness of each thin sample was measured on OPS and the values obtained are show in Table I. Two types of oil were used as liquid samples: soy oil and linseed oil. The thin materials and liquids were analyzed on the first setup in a one-dimensional way, other materials like plant leaves, a steel nut and a cross made with single-sided adhesive copper conducting tape 3M Code 1181 were recorded in a bi-dimensional scan.

Photovoltaic currents from translucent samples were obtained by the one-dimensional experimental setup described below. Fig. 22 shows the first setup used in order to obtain photovoltaic current from translucent samples. In this case, a fiber-coupled LASER system with a wavelength of $650 \mathrm{~nm}$ was used (Suaste \& González, 2009; Suaste et al., 2010). This LASER was modulated to a frequency of $3 \mathrm{~Hz}$ with a Beckman Industrial Function Generator; the distance between sample and LASER beam was $1 \mathrm{~cm}$. The electrical contacts (on the lower side face electrode and Pt-wire) of the sensor were connected to an SRS-Low Current Noise Preamplifier in order to obtain photovoltaic current. These signals were registered by an Oscilloscope Agilent which measured their peak to peak voltage.

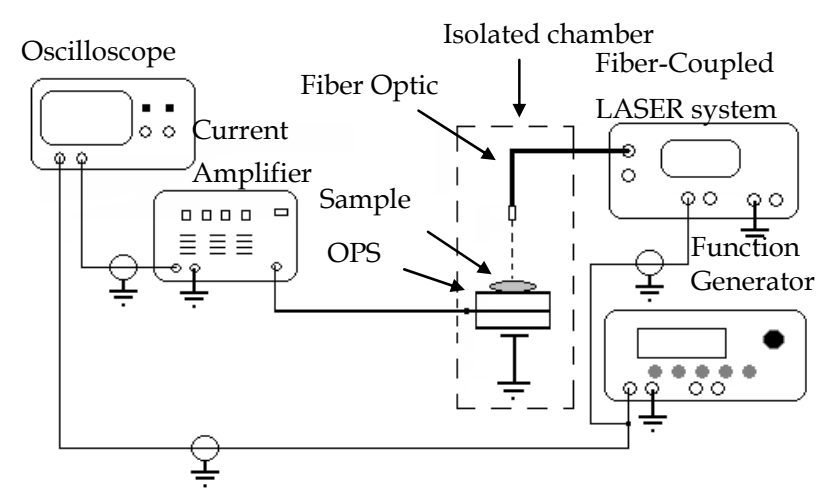

Fig. 22. One-dimensional experimental setup of OPS system.

In the one-dimensional setup, the OPS showed satisfactory results because it reacted to a wide range of detection which allowed to have higher resolution at a higher intensity of illumination. Photovoltaic current was $688 \mathrm{pA}$, in the region of highest illumination intensity, $160 \mathrm{~mW} / \mathrm{cm}^{2}$ for the OPS without sample. The graphic of OPS shows a clear difference among thin materials and liquids, Fig. 23. The OPS recording without samples determines $0 \%$ of opacity; while for the recordings with samples, this percentage increased according to the characteristics of each of them. Table I shows the percentage of opacity at $91.43 \mathrm{~mW} / \mathrm{cm}^{2}$ of illumination; this value was chosen as example of the opacity percentage of each sample. 


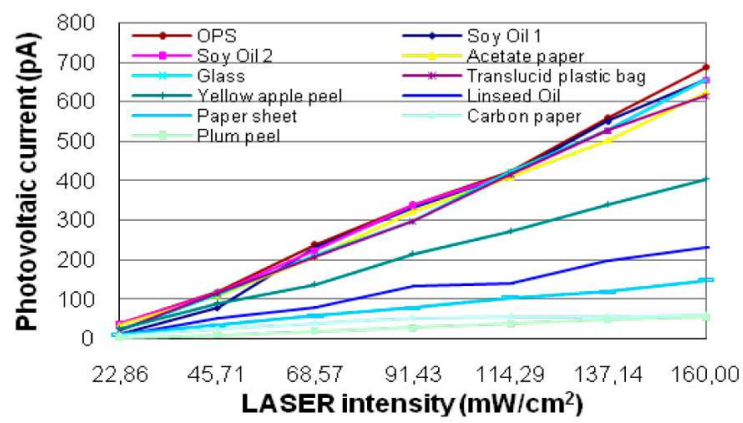

Fig. 23. The OPS detected curves for different liquids and thin solids.

\begin{tabular}{|l|c|c|}
\hline $\begin{array}{l}\text { Liquids and thin materials } \\
\text { samples measured on OPS }\end{array}$ & Thickness $(\mu \mathrm{m})$ & $\%$ of Opacity \\
\hline Plum peel & 76.2 & 91.7 \\
\hline Carbon paper & 36.56 & 84.33 \\
\hline Paper sheet & 101.6 & 76.61 \\
\hline Linseed Oil & 100 & 60.82 \\
\hline Yellow apple peel & 88.9 & 36.84 \\
\hline Transparent Plastic Bag & 63.5 & 12.28 \\
\hline Glass & 152.4 & 12.28 \\
\hline Acetate paper & 109.22 & 5.26 \\
\hline Soy Oil 2 & 100 & 1.17 \\
\hline Soy Oil 1 & 100 & 2.92 \\
\hline
\end{tabular}

Table 1. Opacity percentage of different liquids and thin materials at $91.43 \mathrm{~mW} / \mathrm{cm}^{2}$ of illumination using one-dimensional setup.

The second experimental setup used to obtain 2D opacity images from a plant leaf (Myrtus communis), steel nut and a copper cross is shown in Fig. 24 fiber-coupled LASER system was modulated at the same frequency of the first setup but in this case, a set of lenses which reduce the LASER beam spot to a $0.5 \mathrm{~mm}$ of diameter size was used. The sample was placed on the OPS and both were placed on an X-Y translation microscope stage.

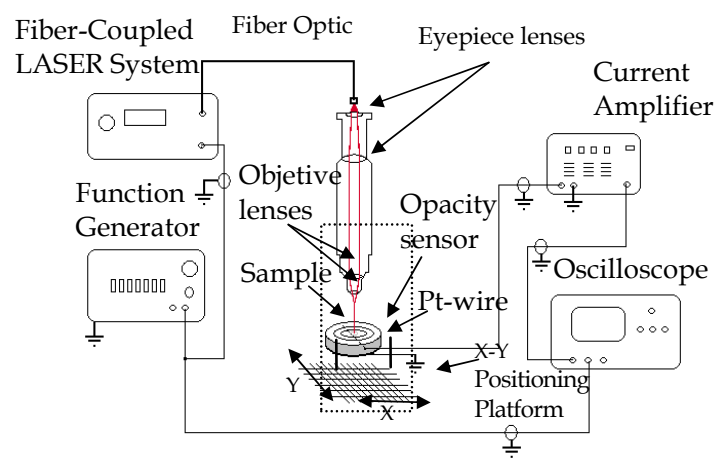

Fig. 24. Bi-dimensional experimental setup of OPS system. 
The analysis of each sample was done millimeter by millimeter with a total of 100 points recording for each sample. The electrical contacts from OPS were connected to an SRS-Low Current Noise Preamplifier in order to obtain 2D scans; these signals records were registered by an Oscilloscope which measured their peak to peak voltage in order to construct a $3 \mathrm{D}$ graphics in which the $\mathrm{Z}$-axis represents the magnitude of the photovoltaic current of each record.

In the bi-dimensional setup, firstly a 2D scan response without sample was obtained; the records were from 1 to 10 in $\mathrm{Y}$-axis and from $a$ to $j$ in X-axis, this graphic shows a great increment in the Pt-wire zone because the ferroelectric domains are very close to each other. The maximum photovoltaic current response was $3.28 \mathrm{pA}$ at $160 \mathrm{~mW} / \mathrm{cm}^{2}$ of illumination; the photovoltaic current response was lower because the LASER beam spot area was smaller. In Fig. 25 is showing the response without simple of OPS.
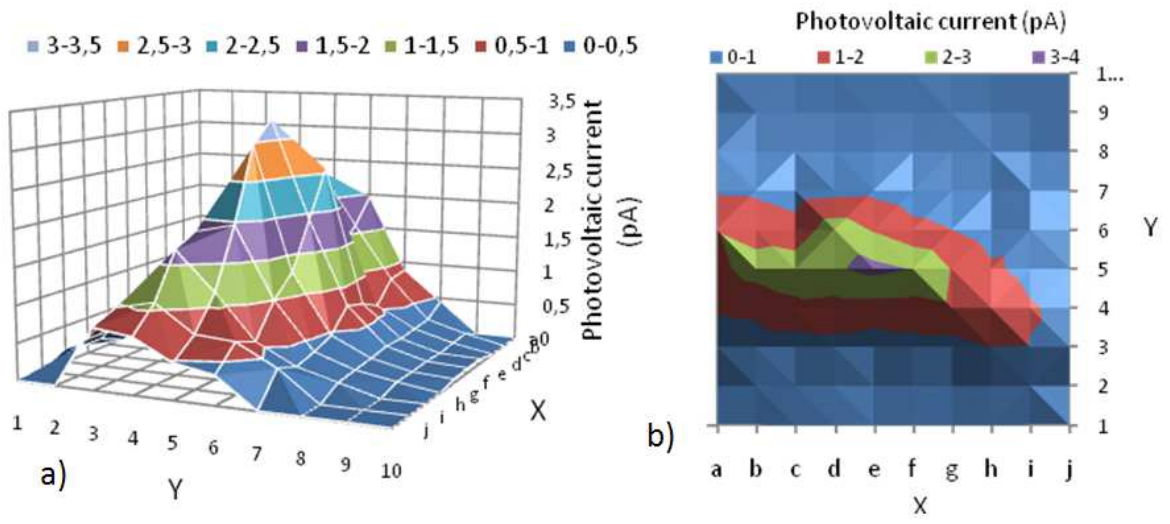

Fig. 25. OPS response without sample in a Bi-dimensional scan, a) 3D representation of OPS, b) Top view of OPS in 2D scan.
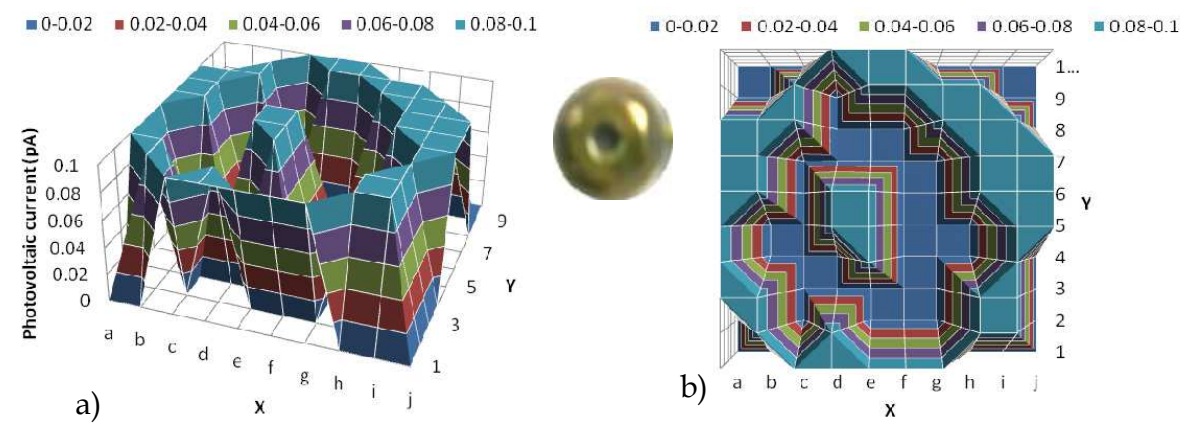

Fig. 26. OPS response with a steel nut, to the right a little picture of the steel nut, a) 3D Graphic, b) 2D scan. 
Figure 26 shows the magnitude of the photovoltaic current of the steel nut registered by the OPS. The edges associated with the graphic are due to the curved form of the nut which dispersed the light and caused that the signal was detected in an area different to the one expected.
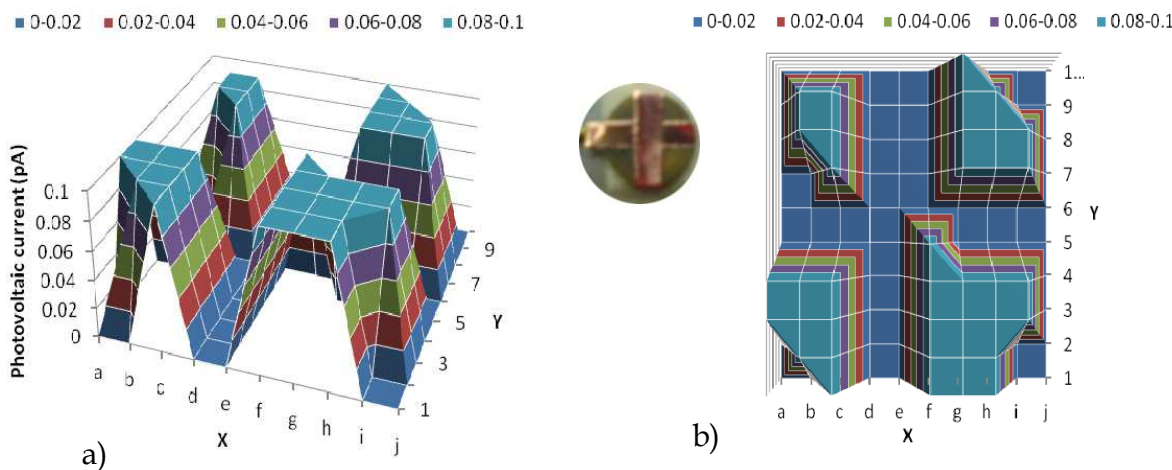

Fig. 27. OPS response with a copper cross, a) 3D graphic, b) 2D scan.

Finally, the acquisition of the signal of the copper cross, on the OPS, was obtained in order to verify each point of the sample so that its image could be constructed, Fig. 27.

These results demonstrated that the OPS allowed to perform 2D scanning and thus generated 3D graphics or images of opacity which varied according to the porcentage of opacity of each sample in the bi-dimensional setup.

Quantitative sensitivity comparison with other types of opacity/transmission would be relative due to the chemical compositions of each sensor and because finally whatever the type of sensor, they only give a percentage measure parameter. The most significant differences among ferroelectric sensors and $\mathrm{Si}$ based sensors are: 1) Si based sensors require electrical external supply and do not have domains; in contrast ferroelectric sensors do not require an external electrical supply; 2) the Si based sensors have greater sensitivity than ferroelectric sensors but these last offer a good response at extreme temperatures, up to $570{ }^{\circ} \mathrm{C}$, according to its chemical composition (ferroelectric phase transition) (Jona \& Shirane, 1993).

\section{Conclusions}

It was shown that the PLZT bulk with Pt-wire has the following advantages: (1) the increase in surface analysis is superior because of the role of Pt-wire that works as a third electrode. (2) The OPS has a useful working range of photovoltaic current because it can capture a power of $330 \mathrm{~mW} / \mathrm{cm}^{2}$ of LASER illumination and give a photovoltaic current response of $1280 \mathrm{pA}$. Furthermore, the range of operating temperature of the OPS reached the Curie temperature of $365{ }^{\circ} \mathrm{C}$, while a standard silicon photo detector operating up to $125{ }^{\circ} \mathrm{C}$ maximum; due to those parameters, the sensor proposed in this work can be used at much higher temperatures and higher illumination intensity as compared to conventional Si based 
OPS. (3) The OPS is easy to manufacture and its size can be modified. The production cost is lower than that of any other semiconductor photo detector. (4) It allows to perform 2D scanning and generate 3D graphics or images of opacity depending on the percentage of opacity of the sample in the bi-dimensional setup. In general, the OPS offers good versatility as a sensor of opacity due to its ferroelectricity and could have novel applications such as before transplant 2D cornea scan in order to verify its opacity, 2D scan opacity of insects (Entomology), before transplant one-dimensional skin scan in order to analyze its color, onedimensional scan on real time of $\mathrm{CO}_{2}$ car emissions (Chamberlain, 2008; Dekking, 1948; Matusik et al., 2002).

Finally, the novel device CCP that has recently been developed such as is described in this chapter, offers a window of opportunity to develop, the circumstances are right for working in diverse fields of applied research.

\section{References}

[Anon], New portable smoke opacity meters introduced. Diesel Progress Engines \& Drives, Vol. 60, Issue 8, pp. 34-35, 1948.

Brody, P. S. (1983). Optomechanical bimorph actuator. Ferroelectrics, Vol. 50(1), 27-32, 00150193

Caro C. (1978). The mechanics of the circulation, Oxford University Press, 0192633236, NYToronto

Chamberlain, D. (2008). The transmission opacity tester. Paper Technology, Vol. 49, pp. 42-4, $0306-252 X$

Dekking, H. M. (1948). Opacity meter for cornea and lens. Ophthalmologica, Vol. 115(4), 4, 219-226

Frerking M. E., (1978). Crystal oscillator design and temperature compensation, Van Nostrand Reinhold Company, New York, 0-442-22459-1

González-Morán C. O., Suaste-Gómez E. (2009). Developed and experimental evidence of a ceramic-controlled piezoelectric bulk implanted with $\mathrm{Pt}$ wire based on PLZT, Ferroelectrics, Vol. 392, 98-106, 0015-0193

Gutierrez-Begovich, D.A.; Suaste-Gomez, E., Frequency modulation via a biological signal using a controlled piezoelectric ceramic, Proceedings of Pan American Health Care Exchanges 2009, pp.7-7, 978-1-4244-3668-2, México City, March 2009

Ichiki M. et al. (2006). Photovoltaic Effect of Crystalline-Oriented Lead Lanthanum Zirconate Titanate in Layered Film Structure, Vol. 45, No. 12, 9115-9118,

Ichiki M., Maeda R., Morikawa Y., Mabune Y. and Nakada T., (2004). Photovoltaic effect of lead lanthanum zirconate titanate in a layered film structure design, Appl. Phys. Lett., Vol. 84, pp. 395-397, 0003-6951

Ichiki M., Maeda R., Morikawa Y., Mabune Y., Nakada T. and Nonaka K. (2005). Preparation and Photovoltaic Properties of Lead Lanthanum Zirconate Titanate in Design of Multilayers, Japanese Journal Appl. Phys., Vol. 44, 6927-6933, 0021-4922

Jaffe B., Cook W. R. (1971). Piezoelectric Ceramics, Academic Press, 0-12-379550-8, London and New York

Jona F., Shirane G. (1993). Ferroelectric crystals, Oxford, 0-486-67386-3, New York 
Kobayashi T., Ichiki M., Furue H., Maeda R., Morikawa Y. and Nonaka K. (2005) Preparation and its photovoltaic effect of ferroelectric film, Key Engineering Materials., Vol. 301, 193-196, 1013-9826

Maini A. K., (2007). Digital Electronics: Principles, Devices and Applications, John Wiley \& Sons Inc., 978-0-470-03214-5, England

Matusik, W; Pfister, H; Ngan, A, et al. (2002). Image-based 3D photography using opacity hulls, ACM Transactions on graphics, Vol. 21 Issue 3, 427-437, 0730-0301

Morikawa Y., Ichiki M. and Nakada T. (2000). Bimorph type optical actuator using PLZT elements, Jnp. Soc. Mech. Eng., Vol. C69, 361-366

Moulson A. J., Herbert J. M. (2003). Electroceramics, John Wiley \& Sons, 047149748 , England

Plonska M., Surowiak Z. (2006). Piezoelectric properties of $x / 65 / 35$ PLZT ceramics depended of the lanthanum (x) ions contents, Molecular and Quantum Acoustics, 27, 207-211,

Qin M., Yao K., Liang Y. C., Shannigrahi S. (2007). Thickness effects on photoinduced current in ferroelectric $\left(\mathrm{Pb}_{0.97} \mathrm{La}_{0.03}\right)\left(\mathrm{Zr}_{0.52} \mathrm{Ti}_{0.48}\right) \mathrm{O}_{3}$ thin films, Journal of Applied Physics, Vol. 101, 014104-1 014104-4, 0021-8979

Spigulis J. (2005). Optical noninvasive monitoring of skin blood pulsations, Appl. Opt. 44, 1850-1857, 0003-6935

Sturman B. I. and Fridkin V. M. (1992). The Photovoltaic and Photorefractive Effects in Noncentrossymetric Materials Vol. 8, Gordon and Breach Science Publishers, 288124498X, New Jersey

Suaste-Gómez E., González-Morán C. O. (2009). Photovoltaic Effect of Lead-Free Piezoelectric Ceramics, $\left(\mathrm{Bi}_{0.5} \mathrm{Na}_{0.5}\right)_{0.935} \mathrm{Ba}_{0.065} \mathrm{TiO}_{3}$ and $\mathrm{Pb}_{0.88}(\mathrm{Ln})_{0.08} \mathrm{Ti}_{0.98} \mathrm{Mn}_{0.02} \mathrm{O}_{3}$ (Ln $=\mathrm{La}, \mathrm{Eu})$, Ferroelectrics, Vol. 386, 70-76, 0015-0193

Suaste-Gómez E., González-Morán C. O. and Flores-Cuautle J. J. A. (2009). Developed and applications of a novel ceramic-controlled piezoelectric due to an implant of Ptwire into the body of sigle disk of $\mathrm{BaTiO}_{3}$ ceramic, Proceedings of WC2009, IFMBE 25/XII, pp. 89-92,", O. Dössel and W. C. Schlegel, 978-3-642-03892-1, Munich, Germany

Suaste-Gómez E., Flores-Cuautle J. J. A., Gónzalez-Morán C. O. (2010). Opacity Sensor Based on Photovoltaic Effect of Ferroelectric PLZT Ceramic With Pt Wire Implant, Sensors Journal, IEEE, vol.10, no.6, 1056-1060, 1530-437X

Tonooka K., Poosanaas P. and Uchino K. (1998). Mechanism of the bulk photovoltaic effect of ferroelectrics, Proceedings of SPIE Volume: 3324, 9780819427687

Touloukian Y. S., Powell R. W., Ho C. Y., Klemens P.G. (1970). Thermophysical Properties of Matter, Vol. 1, Thermal Conductivity: Metallic elements and alloys, IFI/Plenum Press, 306-67021-6, New York

Wai-Kai Chen, (2005). The electrical engineering handbook, AP Series in Engineering Series, Elservier Academic Press, 0121709604, CA USA 


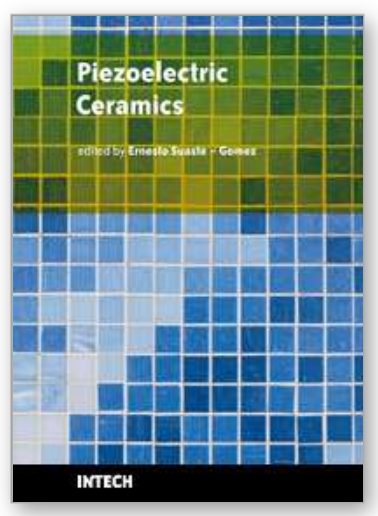

\author{
Piezoelectric Ceramics \\ Edited by Ernesto Suaste-Gomez
}

ISBN 978-953-307-122-0

Hard cover, 294 pages

Publisher Sciyo

Published online 05, October, 2010

Published in print edition October, 2010

This book reviews a big window of opportunity for piezoelectric ceramics, such as new materials, material combinations, structures, damages and porosity effects. In addition, applications of sensors, actuators, transducers for ultrasonic imaging, positioning systems, energy harvesting, biomedical and microelectronic devices are described. The book consists of fourteen chapters. The genetic algorithm is used for identification of RLC parameters in the equivalent electrical circuit of piezoelectric transducers. Concept and development perspectives for piezoelectric energy harvesting are described. The characterization of principal properties and advantages of a novel device called ceramic-controlled piezoelectric with a Pt wire implant is included. Biocompatibility studies between piezoelectric ceramic material and biological cell suspension are exposed. Thus, piezoelectric ceramics have been a very favorable solution as a consequence of its high energy density and the variety of fabrication techniques to obtain bulk or thin films devices. Finally, the readers will perceive a trend analysis and examine recent developments in different fields of applications of piezoelectric ceramics.

\title{
How to reference
}

In order to correctly reference this scholarly work, feel free to copy and paste the following:

Ernesto Suaste-Gomez, Carlos Omar Gonzalez.Moran and Jose De Jesus Agustin Flores-Cuautle (2010). Ceramic-Controlled Piezoelectric: Development, Applications and Potentiality in Electrical and Biomedical Engineering., Piezoelectric Ceramics, Ernesto Suaste-Gomez (Ed.), ISBN: 978-953-307-122-0, InTech, Available from: http://www.intechopen.com/books/piezoelectric-ceramics/ceramic-controlled-piezoelectricdevelopment-applications-and-potentiality-in-electrical-and-biomedi

\section{INTECH}

open science | open minds

\section{InTech Europe}

University Campus STeP Ri

Slavka Krautzeka 83/A

51000 Rijeka, Croatia

Phone: +385 (51) 770447

Fax: +385 (51) 686166

www.intechopen.com

\section{InTech China}

Unit 405, Office Block, Hotel Equatorial Shanghai

No.65, Yan An Road (West), Shanghai, 200040, China 中国上海市延安西路65号上海国际贵都大饭店办公楼 405 单元

Phone: +86-21-62489820

Fax: $+86-21-62489821$ 
(C) 2010 The Author(s). Licensee IntechOpen. This chapter is distributed under the terms of the Creative Commons Attribution-NonCommercialShareAlike-3.0 License, which permits use, distribution and reproduction for non-commercial purposes, provided the original is properly cited and derivative works building on this content are distributed under the same license. 